\title{
The Price Fluctuations in the Regional Agricultural Markets and Their Effect on Agricultural Production Planning
}

\author{
Galina V. Golikova \\ Department of Economics and Organization Management \\ Voronezh State University \\ Voronezh, Russia \\ E-mail: ggalina123@yandex.ru
}

\author{
Natalia V. Shishkina \\ Department of Economic Theory and of the World \\ Economy \\ Voronezh State Agricultural University of a Name of the \\ Emperor Peter I \\ Voronezh, Russia \\ E-mail: natalia.schischkina@yandex.ru \\ Tatiana V. Sabetova \\ Department of Management and Marketing in Agro- \\ industrial Complex \\ Voronezh State Agricultural University of a Name of the \\ Emperor Peter I \\ Voronezh, Russia \\ E-mail: tsabetova@mail.ru
}

\author{
Natalia V. Golikova \\ Department of Economics and Organization Management \\ Voronezh State University \\ Voronezh, Russia \\ E-mail: snv-vrn@mail.ru
}

\begin{abstract}
The article is devoted to the formation of prices for certain agricultural products and its consideration in planning. The authors note that the food and food raw material market can be regarded as an ordinary commodity market, but with some specific features. One of these features is a significant time lag between the decision-making and economic result gained from it. The authors point out the price as one of the most important factors of risk and instability in agricultural markets. Its instability is regarded by business managers as one of the reasons for their refusal of serious strategic planning of their activities.
\end{abstract}

Keywords-agricultural product market; price; crop yield; sales; forecast; current planning; strategic planning

\section{INTRODUCTION}

Russian agriculture remains under severe economic crisis already for over twenty years, even though recently some positive changes were observed is almost every sector of the agro-industrial complex compared to the 1990-es. Economic reformation has led to considerable alterations in the structure of Russian agro-industrial complex. However, it never affected the production efficiency in this sector [1] [2].
Food market is a typical goods market, which differs from all the other goods markets only due to the great importance of the goods sold, which is food absolutely necessary for human beings. However, in some cases it may be viewed as a raw material market when the processing industry companies buy the 'raw' products from agriculture for their production.

Besides, almost all food products initially come from agricultural sector later passing the processing stage or missing it, like fresh vegetables and fruit, for instance. The final consumer's demand within the food markets is placed by all global population or any smaller territory in question.

II. The Key FActors Determining THE SizE AND STRUCTURE OF THE DEMAND WiTHIN FOOD MARKETS

We may define the key factors determining the size and structure of the demand within food markets, which include:

- physiologically normal standards of food consumption for humans,

- consumer purchasing power, 
factors remain undetermined and unstable. In particular, we point out that, under market price jumpiness and complete lack of individual seller's influence upon them, the manufacturers face great difficulties in selecting the goods they should produce in order to obtain better economic results.

Under that logic, the price for agricultural products should demonstrate certain dependence on the gross yield and crop yield. Taking into account the natural lag between the market changes (including price) and the reaction of the companies, as well as instability of the market environment in general, such dependence might take the following features:

- If we suppose that the market cycle in crop farming has certain beginning, such as start of a new business, for example, in this beginning point the crop acreage shall be defined by the available land and the scientifically grounded crop rotation. Thus, we may consider the given crop acreage as a free variable.

- Under the influence of the natural agrotechnical factors some gross yield is received from this acreage which is the function of the crop yield only.

- If those conditions are the same for the whole region or other territory, then they affect the crop price within its local market.

Food market has distinctly long time lag to any alterations. It takes place due to the duration of the possible short-time period in agriculture which is usually a year, so the companies cannot immediately react to the changes going on within the market and macroeconomic system, even when those changes are of great scale and importance [6].

Company management can be considered as the system of organizational and management functions, where one of the central tasks is planning. The specific features of the agricultural sector of economy, associated with the seasonal production cycle and operation performance within very strict time limits of recommended agrotechnical terms, require its observation during design of the plans of various types in crop farming, animal husbandry, and other branches. Unfortunately, after the transition to market economy, the rejection of command and administrative economic system was taken by many company managers and executives as the possibility for total rejection of planning as the general function. After a while the short-term planning was more or less restored in the agricultural company management, but the strategic planning, according to the opinions of many experts [7], even by now remains misappreciated and used in the very limited way by many companies. Even the production and finance plan presenting the programme of a company's activities for the calendar year coming and designed in the unified form approved by the Ministry for agriculture, is often prepared by the accountants of a company, or not prepared at all.

\section{ANALYSIS OF CROP YIELD AND PRICE FLUCTUATIONS OF VORONEZH REGION}

But we should ask ourselves whether a company can plan its business under the current conditions where so many
- Depending on the price level the companies may somewhat vary the crop acreage structure for the following year, even though such variation still limited by agro-technologies applied. Then the given crop acreage seizes to be free variable and becomes the function of the price.

Understanding, that the situation where a given company can obtain better yield or crop yield tendency opposite to the general trend within its location, is of rather low probability, we draw the conclusion, that the product price shall depend on both the sales volume of the product and the given crop yields. Such hypothesis allows suggestion that such dependence is the more pronounced, the higher territorial level is researched, i.e. more obvious within the district than in one particular company, and even more son within a region or even nationwide.

We have analyzed the data on crop yields, sales volumes, and prices for the key crops in Voronezh region obtained during the last six years and for three territorial levels, including particular farming company, administrative district, and Voronezh region ("Table I"). 


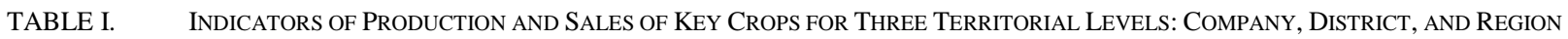

\begin{tabular}{|c|c|c|c|c|c|c|c|}
\hline \multirow[t]{2}{*}{ Crop } & \multirow{2}{*}{ Indicator } & \multicolumn{6}{|c|}{ Years } \\
\hline & & 2011 & 2012 & 2013 & 2014 & 2015 & 2016 \\
\hline 1 & 2 & 3 & 4 & 5 & 6 & 7 & 8 \\
\hline \multicolumn{8}{|c|}{ Agrotech-Garant Khleborodnoye, Ltd. } \\
\hline \multirow{3}{*}{ Wheat } & Crop yield, metric centner per ha & 17.2 & 31.3 & 49.8 & 53.3 & 43.7 & 57.6 \\
\hline & Sales volume, ths metric centner & 11.171 & 61.837 & 87.426 & 35.804 & 80.537 & 54.454 \\
\hline & Price, rubles per centner & 533.3 & 701.5 & 615.6 & 670.9 & 878.9 & 846.4 \\
\hline \multirow{3}{*}{ Barley } & Crop yield, metric centner per ha & 27.0 & 23.3 & 33.1 & 47.2 & 37.2 & 50.7 \\
\hline & Sales volume, ths metric centner & 12.777 & 13.838 & 23.187 & 39.187 & 32.861 & 78.647 \\
\hline & Price, rubles per centner & 483.5 & 591.1 & 592.6 & 312.1 & 764.6 & 732.8 \\
\hline \multirow{3}{*}{ Sugar beetroot } & Crop yield, metric centner per ha & 524.7 & 687.7 & 650.0 & 494.7 & 569.6 & 639.1 \\
\hline & Sales volume, ths metric centner & 302.250 & 511.380 & 362.448 & 346.786 & 320.865 & 584.820 \\
\hline & Price, rubles per centner & 167.8 & 146.6 & 135.9 & 206.1 & 272.5 & 258.9 \\
\hline \multirow{3}{*}{ Sunflower } & Crop yield, metric centner per ha & 24.2 & 20.9 & 25.4 & 39.9 & 33.4 & 32.2 \\
\hline & Sales volume, ths metric centner & 30.467 & 8.616 & 44.766 & 31.949 & 20.224 & 14.262 \\
\hline & Price, rubles per centner & 1093.0 & 1300.4 & 1218.8 & 1075.4 & 2196.2 & 2351.4 \\
\hline 1 & 2 & 3 & 4 & 5 & 6 & 7 & 8 \\
\hline \multicolumn{8}{|c|}{ Anna administrative district } \\
\hline \multirow{3}{*}{ Wheat } & Crop yield, metric centner per ha & 30.4 & 36.5 & 47.8 & 54.6 & 42.6 & 54.2 \\
\hline & Sales volume, ths metric centner & 190.307 & 371.654 & 936.024 & 538.350 & 390.660 & 489.798 \\
\hline & Price, rubles per centner & 491.4 & 682.8 & 578.2 & 600.6 & 763.6 & 786.9 \\
\hline \multirow{3}{*}{ Barley } & Crop yield, metric centner per ha & 28.6 & 29.3 & 28.0 & 37.0 & 34.0 & 37.7 \\
\hline & Sales volume, ths metric centner & 103.449 & 142.265 & 213.881 & 330.950 & 231.351 & 304.926 \\
\hline & Price, rubles per centner & 484.1 & 572.2 & 559.5 & 448.6 & 704.9 & 697.4 \\
\hline \multirow{3}{*}{ Sugar beetroot } & Crop yield, metric centner per ha & 487.8 & 611.4 & 607.0 & 465.2 & 533.9 & 594.5 \\
\hline & Sales volume, ths metric centner & 2285.482 & 3152.149 & 1926.943 & 1572.242 & 1471.493 & 2497.648 \\
\hline & Price, rubles per centner & 150.9 & 125.5 & 134.6 & 188.3 & 265.9 & 250.7 \\
\hline \multirow{3}{*}{ Sunflower } & Crop yield, metric centner per ha & 27.4 & 25.1 & 28.3 & 25.7 & 34.1 & 31.2 \\
\hline & Sales volume, ths metric centner & 122.728 & 186.186 & 341.944 & 272.399 & 279.874 & 264.090 \\
\hline & Price, rubles per centner & 1009.7 & 1392.8 & 1095.6 & 1211.2 & 2156.9 & 2157.2 \\
\hline \multicolumn{8}{|l|}{ Voronezh region } \\
\hline \multirow{3}{*}{ Wheat } & Crop yield, metric centner per ha & 25.5 & 27.0 & 28.9 & 38.8 & 18.4 & 37.9 \\
\hline & Sales volume, ths metric centner & 3453.056 & 11924.940 & 9285.338 & 14000.495 & 12795.507 & 16847.227 \\
\hline & Price, rubles per centner & 466.2 & 696.4 & 523.3 & 651.6 & 834.8 & 792.9 \\
\hline \multirow{3}{*}{ Barley } & Crop yield, metric centner per ha & 21.4 & 22.6 & 21.4 & 28.4 & 24.4 & 26.1 \\
\hline & Sales volume, ths metric centner & 1845.634 & 4196.699 & 3850.148 & 5562.222 & 4306.350 & 4311.846 \\
\hline & Price, rubles per centner & 478.1 & 632.9 & 499.1 & 489.2 & 727.9 & 682.2 \\
\hline 1 & 2 & 3 & 4 & 5 & 6 & 7 & 8 \\
\hline \multirow{3}{*}{ Sugar beetroot } & Crop yield, metric centner per ha & 361.7 & 370.2 & 381.2 & 329.3 & 359.7 & 462.4 \\
\hline & Sales volume, ths metric centner & 41469.397 & 41512.711 & 33479.895 & 27872.566 & 32295.864 & 48027.947 \\
\hline & Price, rubles per centner & 159.1 & 130.8 & 156.2 & 205.0 & 330.0 & 278.9 \\
\hline \multirow{3}{*}{ Sunflower } & Crop yield, metric centner per ha & 21.3 & 18.5 & 15.9 & 19.8 & 23.7 & 22.7 \\
\hline & Sales volume, ths metric centner & 3255.334 & 5189.901 & 6927.882 & 5415.545 & 5916.076 & 5981.889 \\
\hline & Price, rubles per centner & 971.0 & 1414.4 & 1137.0 & 1306.5 & 2176.8 & 2083.7 \\
\hline
\end{tabular}

To make all figures of the "Table I" comparable in scale we re-calculated them as per cent of the average value for each 6-year row (separately for crop yield, sales volume, and price). As a result we obtained the data presented in the "Fig. 1" for particular producing company - Agrotech-Garant Khleborodnoye, Ltd. 


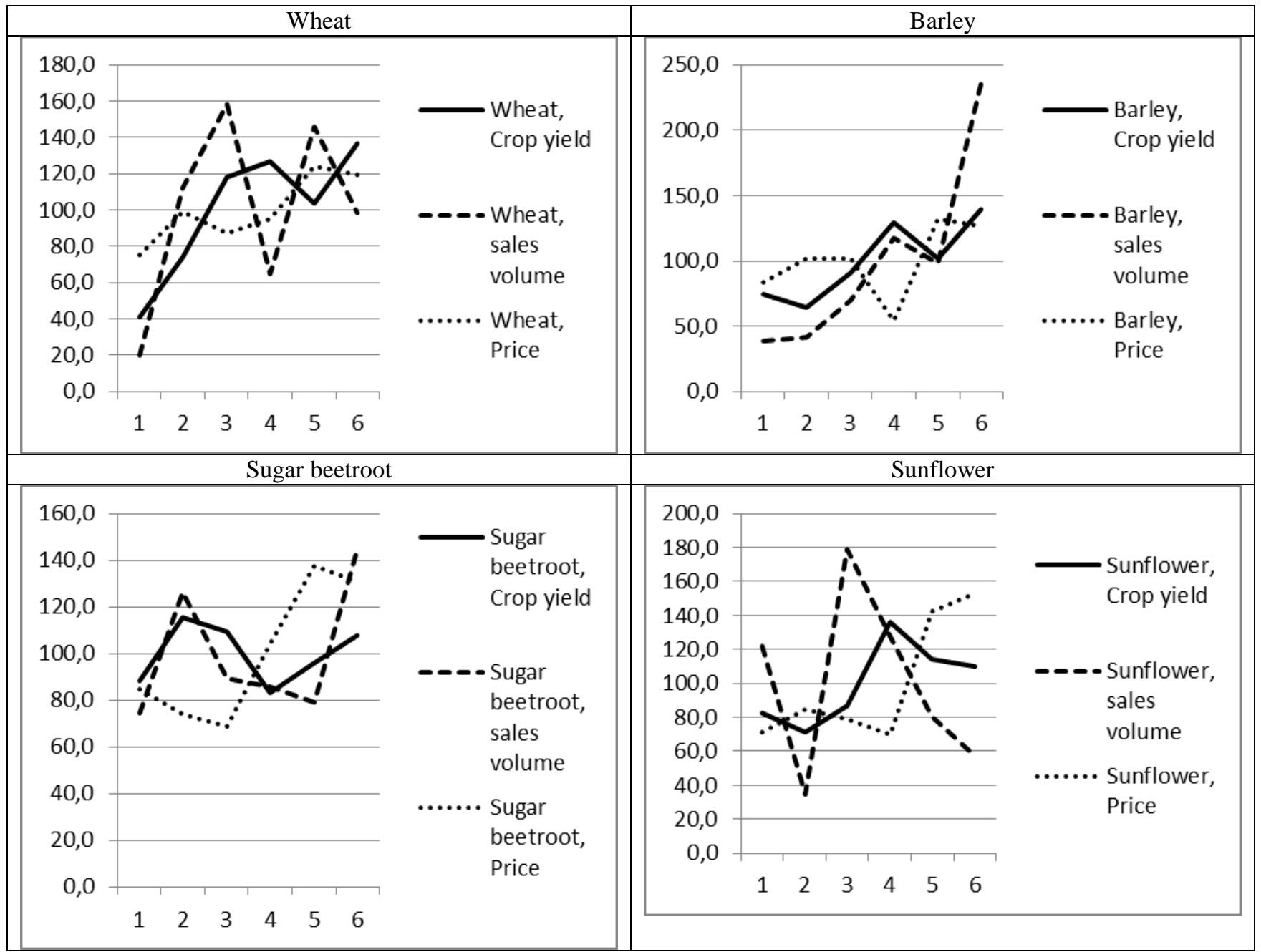

Fig. 1. The dynamics of the indicators for Agrotech-Garant Khleborodnoye, Ltd., \% of the average value, 2011-2016.

As we can see, there is only one crop, for which the predicted dependence is clearly obvious, which is barley. For this crop the price grows after the reduction of crop yield and sales volume, and vice versa. We also suggested, that during the year following the price growth one may expect increase of crop acreage and probably increase of sales volume (if there is no significant crop yield reduction due to some unfavourable conditions). However, we see such tendency only for wheat, and so we have certain reasons to believe it to be probably caused by some other factors, as there is no such connection for other crops. Hence we draw the conclusion that, at least in this particular company, the planning of crop acreage and crop rotation does not depend on short-term market price fluctuations. Nevertheless, the calculations for the other companies demonstrated, that this dependence is not always registered. It seems technically impossible to compare the performance of all companies even within a single district (as there are usually fifteen to twenty large scale companies and about the same number or more farmers), but still our observations proved that the price factor is taken into consideration for planning in about half of the cases, and sometimes it becomes the key or one of the most important factors affecting the selection of crops, acreage definition and even crop rotation, which in our opinion is unacceptable.

We put forward the suggestion that the said dependences are more pronounced at the district level of observation. In the "Fig. 2" the data for Anna administrative district are demonstrated, where, incidentally, Agrotech-Garant Khleborodnoye, Ltd. is located. 


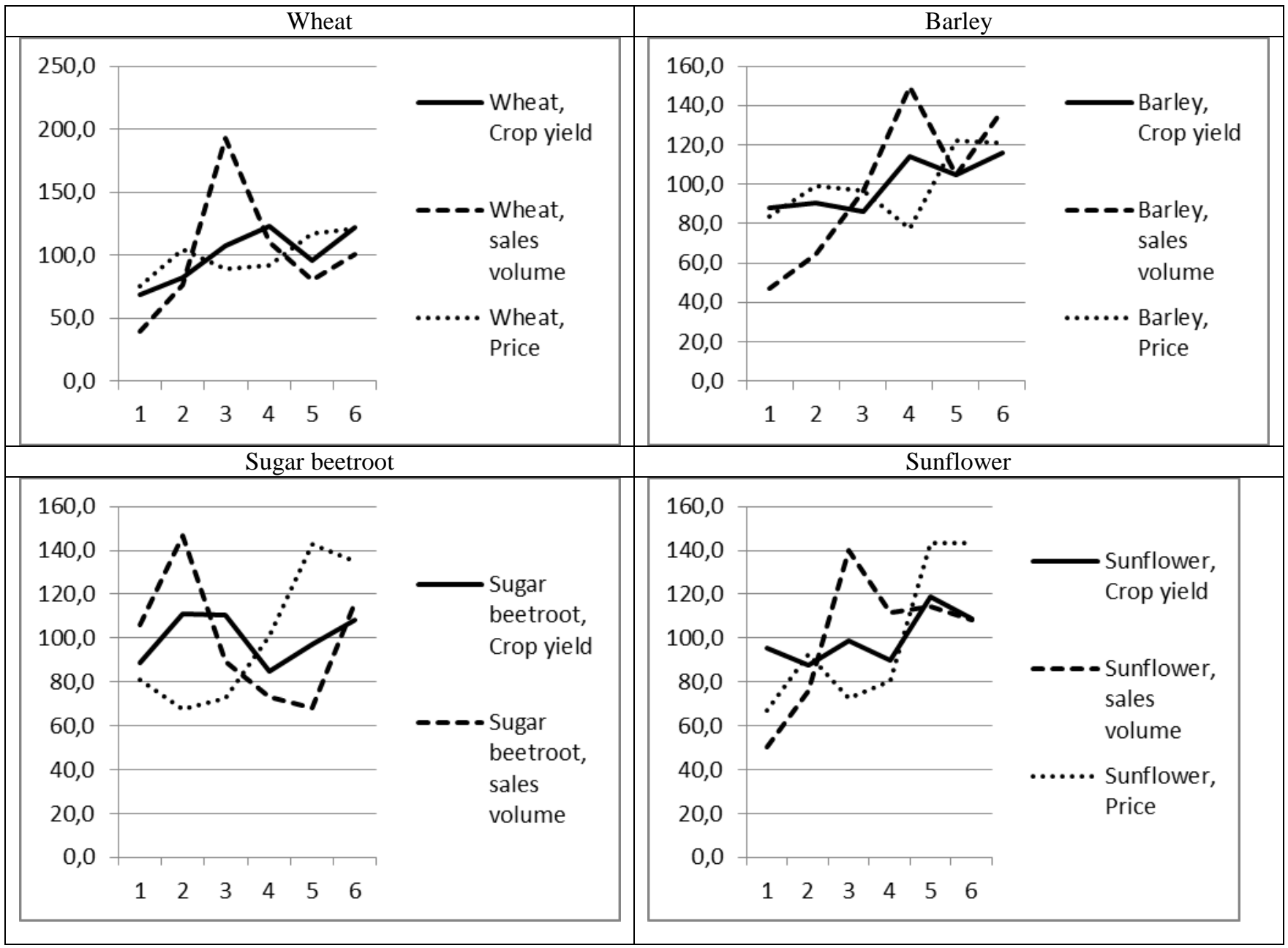

Fig. 2. The dynamics of the indicators for Anna administrative district, $\%$ of the average value, 2011-2016.

As we can see from the "Fig. 2", at the district level the inverse dependence between the price plus crop yield and the sales volume to some extent can be seen for both grain and sugar beetroot. The only crop without this dependence is sunflower. We also should point out somewhat lesser scale of the fluctuations of all indicators here, which could have been expected due to higher level and the indicators carrying some feature of the average values. Nevertheless, we also note that the fluctuations for the district level remain quite considerable, which provides us with the reason to suppose unfavourable deviations in both price and crop yield being the risk factors for agricultural business.

Addressing the similar indicator system for the regional level we observe the tendencies shows in the "Fig. 3". Voronezh region includes Anna administrative district. 


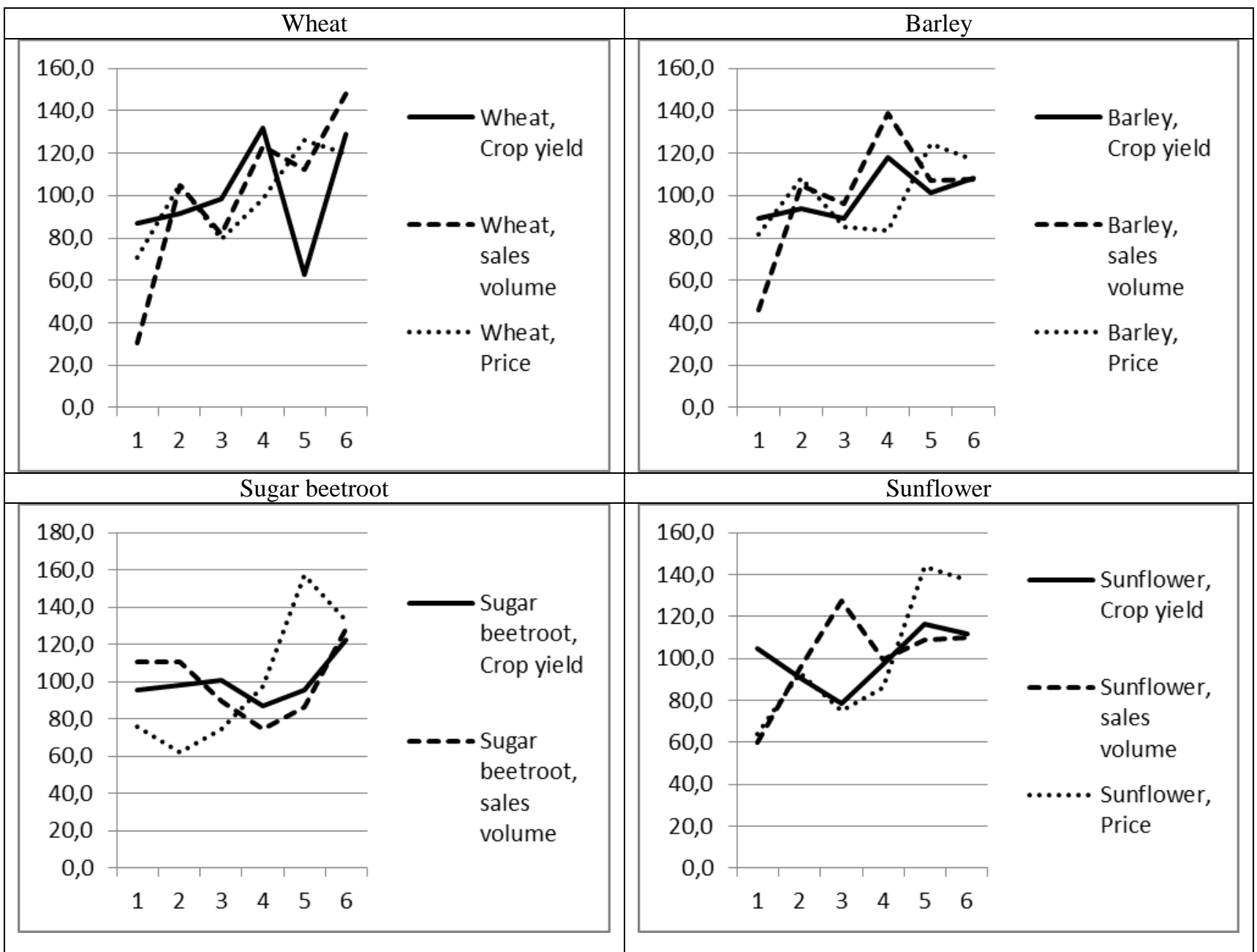

Fig. 3. The dynamics of the indicators for Voronezh region is general, $\%$ of the average value, 2011-2016.

We can see that on the regional level all tendencies are even smoother for nearly all indicators. For grain we see deviation from the hypothetic inverse dependence in 20112012, while for industrial crops the similar situation (price growth accompanied by yield and sales increase) is observed in 2015. However, the latter fact is probably associated with general price growth for all goods in Russia during 2015, than with some specific tendencies in Voronezh regional agriculture. Grain price also grew in 2015, but it did not result in any increase of sales like in industrial crops.

At the same time the following features demonstrated through the viewed data should be pointed out:

- Crop yield fluctuations within our region are so huge that sometimes even increase of the crop acreage does not lead to growth of their gross yield as well as sales volumes within the market. This circumstance is the direct result of Voronezh region being the area of risk farming, meaning that its climate conditions can not eliminate yield fluctuations and even occasional harvest failure whatever agro-technologies are applied.
- Price fluctuations cannot be compared to the production volumes, even in cases when the change trend is excepted, which means inverse. Therefore, it appears to us that the planning of business activity based on the price dynamics only is very unreliable and risky.

- Some of the companies still ground their production plans with the price dynamics instead of other reasons, including agrotechnical factors, which in fact amplifies the indicator jumpiness and does not help in overcoming the typical for agriculture time lag between the decision and its results.

\section{CONCLUSION}

We draw the following conclusions based on the stated above:

First, it is not recommended to use current product prices for production structure planning, as the former fluctuate more rapidly than the companies can possibly react to their changes. It appears much more reasonable to form the plans based on the company's own potential and agrotechnical recommendations, which is the way to do one's best to 
Third, the prices cannot be considered as 'weak signals' in strategic planning. The more reliable ground for any longterms plans is the study of general tendencies in the markets, macroeconomic processes, availability of the given production resources. Meanwhile the current market situation and its fluctuations are too extensive for statistical calculations ("Fig. 4"). neighbours, especially if it did not cause them any considerable prime cost growth.

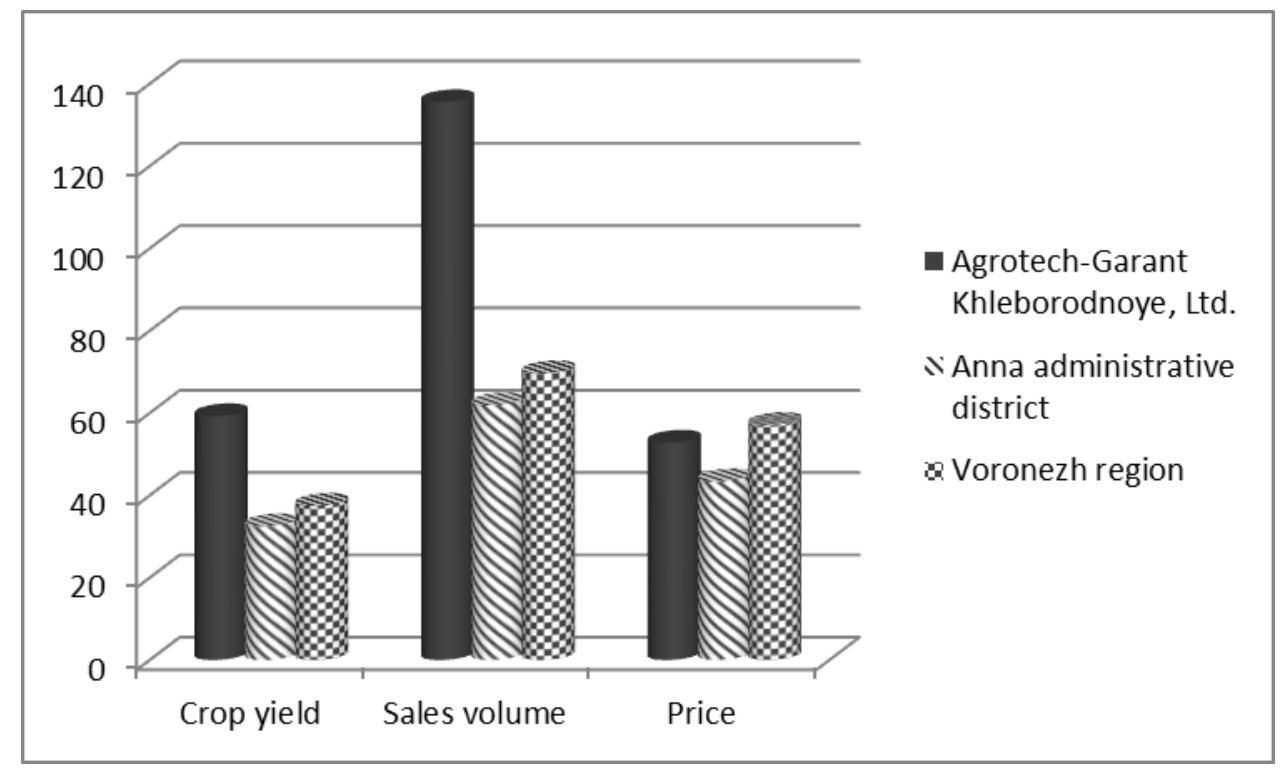

Fig. 4. Maximum abmodality of the indicators, $\%$.

Despite very vast deviations within the dynamic rows for the indicators (the minimum value in the Figure 4 is $32.5 \%$ ) the most stable values are found in crop yields. It is interesting, that price fluctuations demonstrate similar maximum deviations at the company, district and regional levels which are $52.8 \%, 43.4 \%$, and $57.1 \%$ correspondingly. This proves the lack or deficiency of the measures undertaken by the national and regional public authorities for reduction of market jumpiness. The most unstable indicator is sales volumes which are at the same time nearly the direct function of production volumes. This shows complete absence or inconsistency of market forecasting. It also appears that more activities for governmental production regulations might have led to both mitigation of production volume fluctuations (at least at the regional level, if not the single business level) and to some smoothening of price fluctuations.

Russian government should take more responsibility for transformation processes including those in agriculture as a sensitive and strategically important sector of economy [8]. Under these terms arises the necessity for governmental regulations of agriculture as a part of the policy of economically efficiency state.

Creation of efficiency public regulatory system shall naturally precede definition of what the government should and can do for the market economy as a complex system developing in accordance with self-organization patterns in their specific forms typical for social systems. One should take into account selective susceptibility of economic operators to various means of governmental influence considering their assessment of the existing situation. From the point of view of goal attaining the reasonably required level of state regulations is formed, while the budgetary provisions affect the achievable level, defining the selection of the priority influence means. Finally, considering the nature of the stable functional connections existing within the market system, it seems reasonable to detect 'resonance ranges' that may induce the self-organization mechanisms and obtain significant effect of cumulative action of independent elements of the system.

\section{REFERENCES}

[1] Shevtsova N.M., Sabetova T.V. Comparison of central black-soil area regions in terms of competitiveness / Institutional and infrastructural aspects of economics development: Proc. Int. Sci.-Prac. Conf. - Ufa. 2015. - Pp.217-220.

[2] Fedulova I.Yu. Strategic goals and directions of governmental support of Russian agro-industrial complex / Economy and entrepreneurship, 2016, №5(70). - Pp. 957-961.

[3] Fedulova I.Yu. Tendencies and results of investments in innovations / The strategy of sustainable development of Russian regions, 2015, №27. - Pp.70-74.

[4] Treshchevsky Y.I. The system of state support for small and medium entrepreneurship and evaluation of its effectiveness / Treshchevsky, Y.I.,Serebryakova, N.A.,Golikova, G.V., Volkova, S.A.,Volkova, T.A. // Espacios - 2018. - the Vol. 39(11)

[5] Charykova O.G., [etc.] Methodical provisions for improvement of organizational and economic mechanism of Russian grain market development. - Voronezh, 2013.

[6] Vozhdaeva N.G. Agricultural activity planning as a management factor under WTO terms / NGIEI bulletin, 2013, №7(26). - Pp.31-39. 


\section{PRESS}

[7] Zakshevskaya E.V., Zagvozkin M.V. Strategic management at agricultural companies. - Voronezh, 2014.

[8] Golikova G.V. Policy, technologies, and approaches to management of organizational changes // Management of Innovations in SocioEconomic Systems / ed. by Prof. D.A. Endovistky and Prof. E.G. Popkova. - [Springer International Publishing AG], 2017. - P. 31-38 